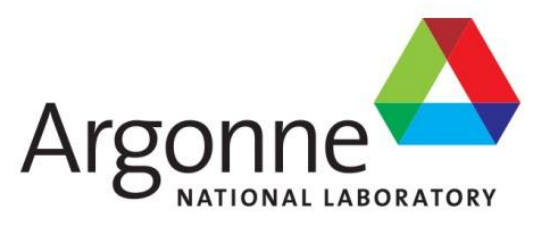

ANL/CSE-13/27

\title{
Centrifugal Contactor Operations for UREX Process Flowsheet
}

Chemical Science and Engineering Division 


\begin{abstract}
About Argonne National Laboratory
Argonne is a U.S. Department of Energy laboratory managed by UChicago Argonne, LLC under contract DE-AC02-06CH11357. The Laboratory's main facility is outside Chicago, at 9700 South Cass Avenue, Argonne, Illinois 60439. For information about Argonne and its pioneering science and technology programs, see www.anl.gov.
\end{abstract}

\title{
DOCUMENT AVAILABILITY
}

Online Access: U.S. Department of Energy (DOE) reports produced after 1991 and a growing number of pre-1991 documents are available free via DOE's SciTech Connect (http://www.osti.gov/scitech/)

Reports not in digital format may be purchased by the public from the National Technical Information Service (NTIS):

U.S. Department of Commerce

National Technical Information Service

5301 Shawnee Rd

Alexandra, VA 22312

www.ntis.gov

Phone: (800) 553-NTIS (6847) or (703) 605-6000

Fax: (703) 605-6900

Email: orders@ntis.gov

Reports not in digital format are available to DOE and DOE contractors from the Office of Scientific and Technical Information (OSTI):

U.S. Department of Energy

Office of Scientific and Technical Information

P.O. Box 62

Oak Ridge, TN 37831-0062

www.osti.gov

Phone: (865) 576-8401

Fax: (865) 576-5728

Email: reports@osti.gov

\footnotetext{
Disclaimer

This report was prepared as an account of work sponsored by an agency of the United States Government. Neither the United States Government nor any agency thereof, nor UChicago Argonne, LLC, nor any of their employees or officers, makes any warranty, express or implied, or assumes any legal liability or responsibility for the accuracy, completeness, or usefulness of any information, apparatus, product, or process disclosed, or represents that its use would not infringe privately owned rights. Reference herein to any specific commercial product, process, or service by trade name, trademark, manufacturer, or otherwise, does not necessarily constitute or imply its endorsement, recommendation, or favoring by the United States Government or any agency thereof. The views and opinions of document authors expressed herein do not necessarily state or reflect those of the United States Government or any agency thereof, Argonne National Laboratory, or UChicago Argonne, LLC.
} 


\section{Centrifugal Contactor Operations for UREX Process Flowsheet}

by

Candido Pereira and George F. Vandegrift

Chemical Science and Engineering Division, Argonne National Laboratory

prepared for

U.S. Department of Energy, National Nuclear Security Administration, Office of Defense Nuclear Nonproliferation

May 15, 2013 



\section{CONTENTS}

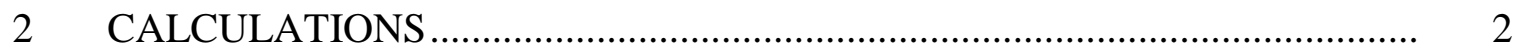

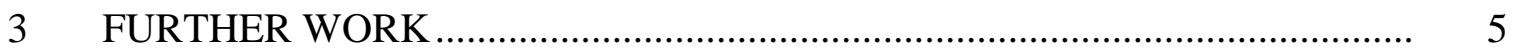

\section{TABLES}

1 Processing Time Requirements for V-2 and V-5 Contactor Banks..................... 2

2 Dimensional CINC Specification for V-2 and V-5 Contactors .......................... 3

3 Hold-up per Section for V-2 and V-5 Contactors Based on UREX Flowsheet .............................................................................................. 4

4 Process Effluent Volumes Generated for V-2 and V-5 Contactors Based

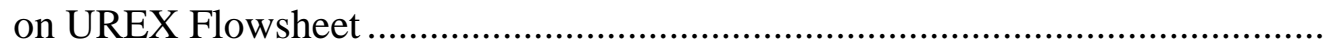




\section{CENTRIFUGAL CONTACTOR OPERATIONS FOR UREX PROCESS FLOWSHEET}

\section{OVERVIEW}

The uranium extraction (UREX) process separates uranium and technetium from the other components of the fuel in nitric acid solution. The time and equipment requirements were evaluated for treatment of 260-L batches of a solution containing $130 \mathrm{gU} / \mathrm{L}$ using commercial annular centrifugal contactors from CINC Industries. An earlier evaluation was done assuming $150 \mathrm{~L}$ of feed solution per batch.

Two different contactor versions from CINC were evaluated, the V-2 and V-5 units. The V-2 has a 2 -in. $(5-\mathrm{cm})$ rotor with a reported maximum through of $1.9 \mathrm{~L} / \mathrm{min}$. We evaluated this version for a throughput of $1 \mathrm{~L} / \mathrm{min}$. The V-5 has a $5-\mathrm{in} .(\sim 12.5-\mathrm{cm})$ rotor with a reported maximum throughput of $19 \mathrm{~L} / \mathrm{min}$. We evaluated this unit for throughputs of 10 and $15 \mathrm{~L} / \mathrm{min}$. The lower-than-maximum throughputs selected for this evaluation are based on Argonne National Laboratory's (Argonne's) ROTOR model, which calculates the operational envelope for a given process O:A ratio based on contactor parameters (weir dimensions, rotor diameter, etc.), the physical properties of the two fluids, and the allowable phase carryover. Because the UREX process designed for this application has O:A ratios ranging from 0.8 to 5.6, adjustments to the weirs in different sections of the contactor bank can broaden the operational envelope for satisfactory separations but throughput will remain short of the equipment maximum. 


\section{CALCULATiONS}

The reference UREX flowsheet consists of four sections with a total of 32 stages. Four additional solvent wash stages were assumed, for a total of 36 stages. Based on processing a single batch, Table 1 shows the process and cumulative time requirements for a V-2 contactor and for a V-5, each operating at maximum throughputs of 10 and $15 \mathrm{~mL} / \mathrm{min}$. As can be seen, the start-up and shutdown times are comparable for all three cases. The uranium and acetohydroxamic acid (AHA) clean-up times assumes a three residence time flush through the entire system at maximum flow. Essentially all of the uranium remaining after process will be collected in the initial pass. If there is additional rinsing, the clean-up is extended an additional 30 to 90 minutes.

As can be seen, the V-2 will require a factor of 10 to 15 increase in the fuel processing time, and a factor of 3 to 6 increase in the overall processing time. The required process times can be reduced by adding multiple lines of the $\mathrm{V}-2$, although this will cause its hold-up and footprint to begin to approach those of the V-5. Table 2 provides some of the parameters for the two different contactor systems from CINC Industries. The "footprint with tubing" assumes that the inter-stage lines will double the lateral dimension of the contactor; this assumption is based on the mount supplied with the individual units by CINC Industries and the orientation shown on the CINC Web site (http://www.cincind.com), in which the interconnect tubing is aligned with the contactor stages. In smaller units (with 2- and 4-cm rotors) Argonne designs place the inter-stage lines perpendicular to the stages; this allows the stages to be situated much closer together, reducing the lateral dimension but increasing the forward and back dimensions in a multi-stage bank. The perpendicular arrangement also allows for easier access to the lines if both the front and back of the bank can be accessed. It may be possible to align

TABLE 1 Processing Time Requirements for V-2 and V-5 Contactor Banks

\begin{tabular}{|c|c|c|c|c|c|c|}
\hline \multirow[b]{2}{*}{ Process Step } & \multicolumn{3}{|c|}{$\begin{array}{c}\text { Test Time } \\
(\min )\end{array}$} & \multicolumn{3}{|c|}{$\begin{array}{l}\text { Cumulative Time } \\
(\min )\end{array}$} \\
\hline & $\begin{array}{c}\mathrm{V}-2 \\
(1 \mathrm{~L} / \mathrm{min}) \\
\end{array}$ & $\begin{array}{c}\mathrm{V}-5 \\
(10 \mathrm{~L} / \mathrm{min})\end{array}$ & $\begin{array}{c}\mathrm{V}-5 \\
(15 \mathrm{~L} / \mathrm{min})\end{array}$ & $\begin{array}{c}\mathrm{V}-2 \\
(1 \mathrm{~L} / \mathrm{min})\end{array}$ & $\begin{array}{c}\mathrm{V}-5 \\
(10 \mathrm{~L} / \mathrm{min})\end{array}$ & $\begin{array}{c}\mathrm{V}-5 \\
(15 \mathrm{~L} / \mathrm{min})\end{array}$ \\
\hline Cold Start & 40.6 & 46.4 & 31.0 & 40.6 & 46.4 & 31.0 \\
\hline Hot Effluent & 3.8 & 4.2 & 3.2 & 44.4 & 50.7 & 34.3 \\
\hline U Effluent & 11.4 & 15.9 & 11.5 & 55.8 & 66.5 & 45.8 \\
\hline All Feed & 972.4 & 97.2 & 64.8 & 1028.2 & 163.8 & 110.6 \\
\hline All Product & 9.9 & 13.9 & 10.2 & 1038.1 & 177.7 & 120.8 \\
\hline All Raffinate & 3.8 & 4.2 & 3.2 & 1041.9 & 181.9 & 124.0 \\
\hline Clean U & 94.2 & 98.8 & 65.4 & 1136.1 & 365.8 & 243.9 \\
\hline Clean AHA & 82.3 & 85.0 & 54.5 & 1218.5 & 280.7 & 189.4 \\
\hline Shutdown & 176.6 & 183.8 & 119.9 & 1395.0 & 365.8 & 243.9 \\
\hline
\end{tabular}


TABLE 2 Dimensional CINC Specification for V-2 and V-5 Contactors

\begin{tabular}{lccccr}
\hline & \multicolumn{2}{c}{$\mathrm{V}-2$} & & \multicolumn{2}{c}{$\mathrm{V}-5$} \\
\cline { 2 - 3 } \cline { 5 - 6 } \multicolumn{1}{c}{ Characteristic } & 1 stage & 36 stages & & 1 stage & 36 stages \\
\hline & & & & & \\
Footprint & $529.0 \mathrm{~cm}^{2}$ & $1.9 \mathrm{~m}^{2}$ & & $1648.4 \mathrm{~cm}^{2}$ & $5.9 \mathrm{~m}^{2}$ \\
Footprint w/Tubing & $1058.0 \mathrm{~cm}^{2}$ & $3.8 \mathrm{~m}^{2}$ & & $3296.7 \mathrm{~cm}^{2}$ & $11.9 \mathrm{~m}^{2}$ \\
Height & $61.0 \mathrm{~cm}$ & $0.6 \mathrm{~m}$ & & $100.0 \mathrm{~cm}$ & $1.0 \mathrm{~m}$ \\
Weight & $12.8 \mathrm{~kg}$ & $460.8 \mathrm{~kg}$ & & $68.2 \mathrm{~kg}$ & $2455.2 \mathrm{~kg}$ \\
Max Throughput & $1.9 \mathrm{~L} / \mathrm{min}$ & & & $19.0 \mathrm{~L} / \mathrm{min}$ & \\
Rotor Speed & $2000-6000 \mathrm{rpm}$ & & & $800-4000 \mathrm{rpm}$ \\
Hold-up & $0.2 \mathrm{~L}$ & & & $3.3 \mathrm{~L}$ & \\
\hline
\end{tabular}

Source: http://www.cincind.com.

the CINC units in this manner, but further analysis is needed. A single V-5 bank will require approximately $12 \mathrm{~m}^{3}$ of space for the arrangement with inline inter-stage lines, while the V-2 would require approximately $4 \mathrm{~m}^{3}$ of space. Three V-2 units would require approximately the same floor space as a single V-5 unit, although the need for access may increase the space needed beyond that for the V-5.

Perhaps the biggest issue in determining the contactor selection is the in-process hold-up and effluent volumes. Table 3 provides the in-process hold-up for the three contactor cases examined here. As can be seen, hold-up in a given section is 10 to 15 times larger for the V-5 as it is for the V-2 contactor. Based on the ROTOR prediction, upon completion of a batch, $\mathrm{V}-2$ will contain approximately $3.7 \mathrm{~L}$ of organic phase and $6.5 \mathrm{~L}$ of aqueous phase, while the V-5 will contain approximately $52 \mathrm{~L}$ of organic phase and 72-80 L of aqueous phase. The composition of the phases will vary significantly across any section during operation, so the clean U process after all feed has been introduced would use cold feeds to force all of the uranium to the strip product prior to shut down. The individual stages should be equipped with drains so that they can be collected separately and kept isolated or subsequently combined. In the reference flowsheet stages 6 through 27 will be relatively concentrated in uranium and there may be some benefit in segregating this material from the rest, but this would come at the cost of additional handling.

Table 4 shows the total volume of effluent generated per processing step for the three operational cases. As can be seen, the largest benefit for the small contactor comes from the reduced start-up and shut-down (clean) volumes. The U product volume is reduced because a substantial fraction of the $U$ is recovered in the clean-up step due to the large contactor hold-up, as can be seen in Table 3. After processing the feed, a substantial fraction of the uranium remains in the contactor. It seems likely that the majority of the uranium would be collected after one residence time, rather than the three assumed here, so the U product volume for the V-5 is likely smaller, perhaps by $50 \%$, but still larger than for the V-2 case. If multiple lines of V-2 are used, hold-up and U product 
TABLE 3 Hold-up per Section for V-2 and V-5 Contactors Based on UREX Flowsheet

\begin{tabular}{|c|c|c|c|c|c|c|}
\hline \multirow[b]{2}{*}{ Hold-up (L) } & \multicolumn{2}{|c|}{$\mathrm{V}-2(1 \mathrm{~L} / \mathrm{min})$} & \multicolumn{2}{|c|}{$\mathrm{V}-5$ (10 L/min) } & \multicolumn{2}{|c|}{ V-5 (15 L/min) } \\
\hline & Organic & Aqueous & Organic & Aqueous & Organic & Aqueous \\
\hline Extraction & 0.654 & 1.355 & 8.818 & 15.316 & 8.726 & 17.550 \\
\hline Scrub 1 & 1.132 & 1.181 & 17.561 & 12.104 & 18.488 & 11.442 \\
\hline Scrub 2 & 0.915 & 0.888 & 14.333 & 8.962 & 15.145 & 8.167 \\
\hline Strip & 0.816 & 2.175 & 10.049 & 25.106 & 9.483 & 29.777 \\
\hline Wash 1 & 0.099 & 0.635 & 0.487 & 7.635 & 0.073 & 9.644 \\
\hline Wash 2 & 0.033 & 0.212 & 0.162 & 2.545 & 0.024 & 3.215 \\
\hline Overall & 3.650 & 6.446 & 51.411 & 71.667 & 51.939 & 79.795 \\
\hline
\end{tabular}

TABLE 4 Process Effluent Volumes Generated for V-2 and V-5 Contactors Based on UREX Flowsheet

\begin{tabular}{|c|c|c|c|}
\hline \multirow[b]{2}{*}{ Process Step } & \multicolumn{3}{|c|}{ Process Volumes (L) } \\
\hline & $\begin{array}{c}\mathrm{V}-2 \\
(1 \mathrm{~L} / \mathrm{min}) \\
\end{array}$ & $\begin{array}{c}\mathrm{V}-5 \\
(10 \mathrm{~L} / \mathrm{min})\end{array}$ & $\begin{array}{c}\mathrm{V}-5 \\
(15 \mathrm{~L} / \mathrm{min}) \\
\end{array}$ \\
\hline Start-up Raffinate & 15 & 168 & 168 \\
\hline Start-up Product & 22 & 254 & 255 \\
\hline Process Raffinate & 390 & 773 & 778 \\
\hline U Product & 592 & 1,174 & 1,181 \\
\hline Clean Raffinate & 1,325 & 307 & 295 \\
\hline Clean Product & 134 & 1,384 & 1,331 \\
\hline Wash 1 & 2,269 & 5,950 & 5,953 \\
\hline Wash 2 & 2,269 & 5,950 & 5,953 \\
\hline
\end{tabular}

volumes begin to approach those calculated for the V-5 here, because of the multiple units. These numbers suggest that there is substantial benefit, particularly for the larger contactors, if the processes are run continuously. Batch operation seems to favor smaller units. 


\section{FURTHER WORK}

The analysis shown here is a first cut at the contactor requirements. Clearly a systematic study needs to be done regarding the relative benefits of the longer process times for the smaller units versus the larger liquid volumes required for the larger units. The mode in which the facility is operated will have a substantial impact. If operation in continuous mode is viable, or if processing can be staggered, the contactor clean-up steps can be eliminated and substantial reduction in waste volumes can be achieved.

There is substantial room for optimization of contactor design. Commercial units tend to be one-size-fits-all, with substantial rework done to meet user-specific requirements. One example mentioned already was the inter-stage line orientation. As contactors become larger, vibration becomes more significant, so mounts must be designed to mitigate the effects of vibration, particularly if a large number of units are mounted in tandem, as will be necessary for UREX. The weirs within the rotors can be optimized to specific separations using the ROTOR model to improve either throughput or stage efficiency, both of which will potentially reduce equipment requirements. The vanes at the base of the housing will also impact the operation of the contactor. CINC units come with curved vanes that improve separation but reduce mixing. An analysis of vane orientation and height can be done for the specific system of interest, particularly as the different sections of the bank operate at very different O:A ratios. Costs can also be reduced if variable-speed motors are replaced with single-speed motors, if these are determined to be sufficient for the desired separation. 



\section{Argonne}

\section{Chemical Science and Engineering Division}

Argonne National Laboratory

9700 South Cass Avenue, Bldg. 205

Argonne, IL 60439-4837

www.anl.gov

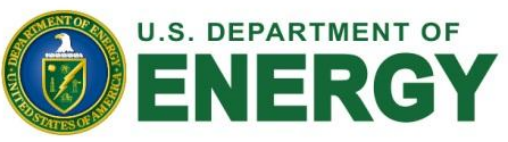

Argonne National Laboratory is a U.S. Department of Energy

laboratory managed by UChicago Argonne, LLC 